\title{
Regulation of bilirubin clearance by ligand-activated transcription factors of the endo- and xenobiotic metabolism system
}

\begin{abstract}
Karl Walter Bock*
Department of Toxicology, Institute of Pharmacology and Toxicology, University of Tübingen, Tübingen, Germany *Correspondence: bock@uni-tuebingen.de
\end{abstract}

Bilirubin, the product of heme catabolism, represents an important endobiotic of the endo-and xenobiotic metabolism system including drug-metabolizing enzymes, drug transporters, and drug-inducible ligandactivated transcription factors (LATFs). Bilirubin is of clinical concern since severe neonatal jaundice may lead to "kernicterus" and neurotoxicity (Kapitulnik, 2004). Hyperbilirubinemia in the newborn is particularly a problem in preterm infants owing to more profound hemolysis, and immaturity of liver function. However, bilirubin is also an interesting antioxidant which may attenuate atherosclerosis (Lin et al., 2008). Hence, bilirubin synthesis and its catabolism has to be strictly controlled. The key to bilirubin's elimination is glucuronidation by UDP-glucuronosyltransferase UGT1A1. However, alternative pathways of bilirubin catabolism have also been observed. For example, the dioxin TCDD, a "classical" ligand of the Ah receptor (AhR) stimulates bilirubin elimination in congenitally jaundiced, UGT1A1-defective Gunn rats (Kapitulnik and Ostrow, 1977). Furthermore, bilirubin itself activates the AhR postnatally, leading to increased transcription of CYP1A1 and CYP1A2 in Gunn rats (Kapitulnik and Gonzalez, 1993). Bilirubin and its extrahepatically formed glucuronides are taken up from blood into hepatocytes by OATP1B1 and OATP1B3 (Nies et al., 2008). Following conjugation bilirubin glucuronides are biliary secreted by ABCC2.

UGT1A1 and all the above transporters are transcriptionally regulated by the constitutive androstane receptor CAR (Huang et al., 2003). In CAR-defective mice phenobarbital-mediated induction of these proteins is absent. When human CAR is transfected into CAR-null mice phenobarbital and bilirubin itself activate CAR, the latter finding suggesting homeostatic control between enzyme substrate and activation of its major transcription factor. Bilirubin is a ligand of the AhR, a multifunctional transcription factor which induces a different set of genes than CAR in the drug metabolism system (Nguyen and Bradfield, 2008). It was discovered by the induction of aryl hydrocarbon metabolism and as mediator of dioxin toxicity. However, the AhR is also involved in development, cell proliferation, differentiation, and immune biology. The importance of the AhR in UGT1A1 induction has been demonstrated in human hepatocyte cultures treated with 3-methylcholanthrene (Ritter et al., 1999). Notably, phenobarbital and bilirubin are not ligands of CAR but activate CAR via phosphorylation/dephosphorylation pathways (Timsit and Negishi, 2007). Binding sites for CAR and the AhR have been identified in a 290-bp cluster of the human UGT1A1, termed gtPBREM (phenobarbital responsive enhancer module; Figure 1; Sugatani et al., 2005). The gtPBREM cluster contains binding sites for a number of ligand-activated transcription factors including pregnane $\mathrm{X}$ receptor (PXR), glucocorticoid receptors GR1 and GR2, CAR, antioxidant-responsive Nrf2 (Yueh and Tukey, 2007), AhR, and fibrate-inducible peroxisome proliferator-activated receptor PPAR $\alpha$ (SenekoEffenberger et al., 2007). It is important to note that the CAR binding site (gtNR1) plays a central role in UGT1A1 induction by both CAR and PXR, which is supported by site-directed mutagenesis and electrophoretic mobility shift assays (Sugatani et al., 2005). The cluster appears to be evolutionary conserved since the same arrangement of LATF-binding sites was found in the baboon (Caspersen et al., 2007). Allelic variants involved in bilirubin clearance have also been detected in the gtPBREM cluster. For example, the (TA) 7 promoter polymorphism UGT1A1*28, responsible for Gilbert's syndrome, is often in linkage disequilibrium with the T3279G polymorphism in the gtPBREM cluster (Sugatani et al., 2008).

\section{PERINATAL UGT1A1 INDUCTION}

It is tempting to speculate that the gtPBREM cluster of UGT1A1 is related to perinatal UGT1A1 induction and bilirubin homeostasis in the adult (Bock and Köhle, 2010; Bock, 2011). In perinatal stressful conditions glucocorticoids may be involved in UGT1A1 induction by CAR and PXR (Pascussi et al., 2008). In addition to CAR (Huang et al., 2003), activated PXR has also been demonstrated to induce UGT1A1 and enhance bilirubin clearance (Xie et al., 2003). With regard to AhR-mediated induction evidence was obtained that both AhR and Nrf2 are required for UGT induction (Yeager et al., 2009). Interestingly, CAR was found to be low in neonatal livers. Hence, the deficit of CAR activity may contribute to neonatal jaundice (Huang et al., 2003).

\section{BILIRUBIN'S ANTIOXIDANT FUNCTION}

Ligand-activated transcription factors which bind in the distal gtPBREM cluster are operating in concert with other transcription factors such as HNF1 and HNF4 and with multiple factors of the proximal promoter. This is demonstrated by the (TA) and T3279G polymorphisms which synergistically reduce CAR- and AhR-mediated UGT1A1 induction not only in transfected cells (Sugatani et al., 2008) but also in human liver samples (Li et al., 2009). Decreased UGT1A1 expression leads to increased serum bilirubin which may contribute to bilirubin's antioxidant function (Stocker et al., 1987a). Albumin-bound bilirubin or conjugated bilirubin have also been shown to exhibit antioxidant activity (Stocker et al., 1987b; Wu et al., 1996; Kapitulnik and Maines, 2009). Evidence was obtained that heme oxygenase/biliverdin reductase activity and biliverdin-bilirubin redox cycles are 


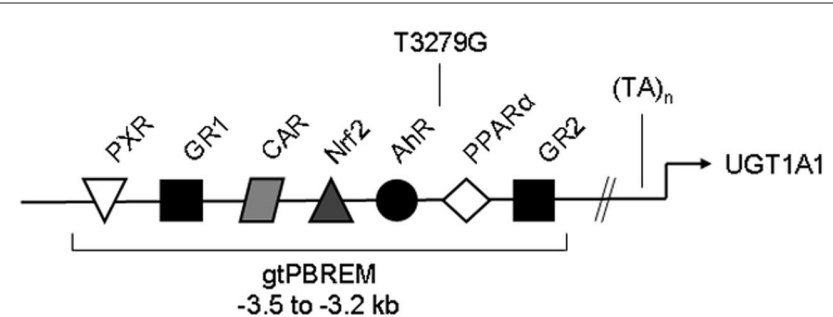

FIGURE 1 | Schematic illustration of allelic variants and the position of response elements binding ligand-activated transcription factors in the enhancer/promoter region of human UGT1A1. Positions are taken from Sugatani et al. (2005), and Bock and Köhle (2010). For discussion see text.

essential for bilirubin's antioxidant and local atheroprotective functions (Baranano et al., 2002). The antioxidant action of bilirubin for lipids can be complementary to glutathione (Sedlak et al., 2009). Bilirubin may be particularly effective in reducing lipid peroxides as it easily enters the lipid environment (Zucker et al., 1999). However, bilirubin catabolism by hepatic UGT1A1 activity is also decisive for bilirubin's antioxidant function, as evidenced by many epidemiologic studies with UGT1A1*28 homozygotes (Lin et al., 2008; Bock and Köhle, 2010, for references). Notably, UGT1A1-regulating LATFs may be therapeutic targets (Kapitulnik and Maines, 2009; Navarro et al., 2009). In conclusion, bilirubin has both neurotoxic and antioxidant functions which are keeping clinicians and basic scientists busy.

\section{ACKNOWLEDGMENTS}

I apologize for often citing reviews instead of original papers.

\section{REFERENCES}

Baranano, D. E., Rao, M., Ferris, C. D., and Snyder, S. H. (2002). Biliverdin reductase: a major physiologic cytoprotectant. Proc. Natl. Acad. Sci. U.S.A. 99, $16093-16098$.

Bock, K. W. (2011). From differential induction of UDP-glucuronosyltransferases in rat liver to characterization of responsible ligand-activated transcription factors, and their multilevel crosstalk. Biochem. Pharmacol. 82, 9-16.

Bock, K. W., and Köhle, C. (2010). Contributions of the Ah receptor to bilirubin homeostasis and its antioxidative and atheroprotective functions. Biol. Chem. 391, 645-653.

Caspersen, C. S., Reznik, B., Weldy, P. L., Abildskov, K. M., Stark, R. I., and Garland, M. (2007). Molecular cloning of the baboon UDP-glucuronosyltransferase 1A gene family. Evolution of the primate UGT1 locus and relevance for models of human drug metabolism. Pharmacogenet. Genomics 17, 11-24.

Huang, W., Zhang, J., Chua, S. S., Quatanani, M., Han, Y., Granata, R., and Moore, D.D. (2003). Induction of bilirubin clearance by the constitutive androstane receptor (CAR). Proc. Natl. Acad. Sci. U.S.A. 100, 4156-4161.
Kapitulnik, J. (2004). Bilirubin: an endogenous product of heme degradation with both cytotoxic and cytoprotective properties. Mol. Pharmacol.66, 773-779.

Kapitulnik, J., and Gonzalez, F. J. (1993). Marked endogenous activation of the CYP1A1 and CYP1A2 genes in the congenitally jaundiced Gunn rat. Mol. Pharmacol. 43, 722-725.

Kapitulnik, J., and Maines, M. D. (2009). Pleiotropic functions of biliverdin reductase: cellular signaling and generation of cytoprotective and cytotoxic bilirubin. Trends Pharmacol. Sci. 30, 129-137.

Kapitulnik, J., and Ostrow, J. D. (1977). Stimulation of bilirubin catabolism in jaundiced Gunn rats by an inducer of microsomal mixed-function monooxygenases. Proc. Natl. Acad. Sci. U.S.A. 75, 682-685.

Li, Y., Buckley, D., Wang, S., Klaassen, C. D., and Zhong, X. B. (2009). Genetic polymorphisms in the TATA box and upstream phenobarbital-responsive enhancer module of the UGT1A1 promoter have combined effects on UDP-glucuronosyltransferase 1A1 transcription mediated by constitutive androstane receptor, pregnane $\mathrm{X}$ receptor, or glucocorticoid receptor in human liver. Drug Metab. Dispos. 37, 1978-1986.

Lin, J. P., O’Donnell, C. J., Schwaiger, J. P., Cupples, L. A., Lingenhel, A., Hunt, S. C., Yang, S., and Kronenberg, F. (2008). Association between the UGT1A1*28 allele, bilirubin levels, and coronary heart disease in the Framingham Heart Study. Circulation 114, 1476-1481.

Navarro, S. L., Peterson, S., Chen, C., Makar, K. W., Schwarz, Y., King, I. B., Li, S. S., Li, L., Kestin, M., and Lampe, J. W. (2009). Cruciferous vegetables feeding alters UGT1A1 activity: diet- and genotype-dependent changes in serum bilirubin in a controlled feeding trial. Cancer Prev. Res. (Phila.) 2, 345-352.

Nguyen, L. P., and Bradfield, C. A. (2008). The search for endogenous activators of the aryl hydrocarbon receptor. Chem. Res. Toxicol. 21, 102-116.

Nies, A. T., Schwab, M., and Keppler, D. (2008). Interplay of conjugating enzymes with OATP uptake transporters and ABCC/MRP efflux pumps in the elimination of drugs. Expert Opin. Drug Metab. Toxicol. 4, 545-568.

Pascussi, J. M., Gerbal-Chaloin, S., Duret, C., DaujatChavanieu, M., Vilarem, M. J., and Maurel, P. (2008). The tangle of nuclear receptors that controls xenobiotic metabolism and transport: crosstalk and consequences. Annu. Rev. Pharmacol. Toxicol. 48, 1-32.

Ritter, J. K., Kessler, F. K., Thompson, M. T., Grove, A. D., Auyeung, D. J., and Fisher, R. A. (1999). Expression and inducibility of the human bilirubin UDP-glucuronosyltransferase UGT1A1 in liver and cultured primary hepatocytes: evidence for both genetic and environmental influences. Hepatology $30,476-484$.
Sedlak, T. W., Saleh, M., Higginson, D. S., Paul, B. D., Juluri, K. R., and Snyder, S. H. (2009). Bilirubin and glutathione have complementary antioxidant and cytoprotective roles. Proc. Natl. Acad. Sci. U.S.A. 106, 5171-5176.

Seneko-Effenberger, K., Chen, S., Brace-Simokrak, E., Bonzo, J. A., Yueh, M. F., Argikar, U., Kaeding, J. Trottier, J., Remmel, R. P., Ritter, J. K., Barbier, O., and Tukey, R. H. (2007). Expression of the human UGT1 locus in transgenic mice by 4-chloro-6-(2,3xylidino)-2-pyrimidinylthioacetic acid (WY-14643) and implications on drug metabolism through peroxisome proliferator-activated receptor $\alpha$ activation. Drug Metab. Dispos. 35, 419-427.

Stocker, R., Yamamoto, Y., McDonagh, A. F., Glazer, A. N., and Ames, B. N. (1987a). Bilirubin is an antioxidant of possible physiological importance. Science 235. 1043-1046.

Stocker, R., Glazer, A. N., and Ames, B. N. (1987b). Antioxidant activity of albumin-bound bilirubin. Proc. Natl. Acad. Sci. U.S.A. 84, 5918-5922.

Sugatani, J., Mizushima, K., Kakizaki, S., Tagaki, H., Mori, M., Ikari, A., and Miva, M. (2008). Transcriptional regulation of human UGT1A1 expression through distal and proximal promoter motifs: implications of defects of the UGT1A1 gene promoter. Naunyn Schmiedebergs Arch. Pharmacol. 377, 597-605.

Sugatani, J., Sueyoshi, T., Negishi, M., and Miva, M. (2005). Regulation of the human UGT1A1 gene by nuclear receptors constitutive active/androstane receptor, pregnane $\mathrm{X}$ receptor and glucocorticoid receptor. Meth. Enzymol. 400, 92-104.

Timsit, Y. E., and Negishi, M. (2007). CAR and PXR: the xenobiotic-sensing receptors. Steroids 72, 231-246.

Wu, T. W., Fung, K. P., Wu, J., Yang, C. C., and Weisel, R. D. (1996). Antioxidation of human low density lipoprotein by unconjugated and conjugated bilirubins. Biochem. Pharmacol. 51, 859-862.

Xie, W., Yeuh, M. F., Radominska-Pandya, A., Saini, S. P. S., Negishi, Y., Bottroff, B. S., Cabrera, G. Y., Tukey, R. H., and Evans, R. M. (2003). Control of steroid, heme, and carcinogen metabolism by nuclear pregnane $\mathrm{X}$ receptor and constitutive androstane receptor. Proc. Natl. Acad. Sci. U.S.A. 100, 4150-4155.

Yeager, R. L., Reisman, S.A.,Aleksunes, L. M., and Klaassen, C.D. (2009). Introducing the "TCDD-inducible AhRNrf2 gene battery." Toxicol. Sci. 111, 238-246.

Yueh, M. F., and Tukey, R. H. (2007). Nrf2-Keap1 signaling pathway regulates human UGT1Al expression in vitro and transgenic UGT1 mice. J. Biol. Chem. 282, 8749-8758.

Zucker, S. D., Goessling, W., and Hoppin, A. G. (1999). Unconjugated bilirubin exhibits spontaneous diffusion through model lipid bilayers and native hepatocyte membranes. J. Biol. Chem. 274, 10852-10862.

Received: 20 October 2011; accepted: 06 December 2011; published online: 26 December 2011.

Citation: Bock KW (2011) Regulation of bilirubin clearance by ligand-activated transcription factors of the endo-and xenobiotic metabolism system. Front. Pharmacol. 2:82. doi: 10.3389/fphar.2011.00082

This article was submitted to Frontiers in Drug Metabolism and Transport, a specialty of Frontiers in Pharmacology. Copyright $(\odot 2011$ Bock. This is an open-access article distributed under the terms of the Creative Commons Attribution Non Commercial License, which permits non-commercial use, distribution, and reproduction in other forums, provided the original authors and source are credited. 